\title{
Review
}

\section{Weaning from mechanical ventilation}

Inmaculada Alía and Andrés Esteban

Hospital Universitario de Getafe, Madrid, Spain

Received: 16 November 1999

Accepted: 21 January 2000

Published: 18 February 2000
Crit Care 2000, 4:72-80

(c) Current Science Ltd

\begin{abstract}
Practice guidelines on weaning should be based on the results of several well-designed randomized studies performed over the last decade. One of those studies demonstrated that immediate extubation after successful trials of spontaneous breathing expedites weaning and reduces the duration of mechanical ventilation as compared with a more gradual discontinuation of ventilatory support. Two other studies showed that the ability to breathe spontaneously can be adequately tested by performing a trial with either T-tube or pressure support of $7 \mathrm{cmH}_{2} \mathrm{O}$ lasting either 30 or $120 \mathrm{~min}$. In patients with unsuccessful weaning trials, a gradual withdrawal for mechanical ventilation can be attempted while factors responsible for the ventilatory dependence are corrected. Two randomized studies found that, in difficult-to-wean patients, synchronized intermittent mandatory ventilation (SIMV) is the most effective method of weaning.
\end{abstract}

Keywords: discontinuation, intermittent mandatory ventilation, mechanical ventilation, pressure support, respiratory rate/tidal volume ratio, spontaneous breathing trials, T-tube, weaning

\section{Introduction}

Weaning from mechanical ventilation can be defined as the process of abruptly or gradually withdrawing ventilatory support. Two large multicenter studies $[1,2]$ have demonstrated that mechanical ventilation can be discontinued abruptly in approximately $75 \%$ of mechanically ventilated patients whose underlying cause of respiratory failure has either improved or been resolved. The remaining patients will need progressive withdrawal from mechanical ventilation.

Weaning from mechanical ventilation usually implies two separate but closely related aspects of care, discontinuation of mechanical ventilation and removal of any artificial airway. The first problem the clinician faces is how to determine when a patient is ready to resume ventilation on his or her own. Several studies [1-5] have shown that a direct method of assessing readiness to maintain spontaneous breathing is simply to initiate a trial of unassisted breathing. Once a patient is able to sustain spontaneous breathing, a second judgement must be made regarding whether the artificial airway can be removed. This decision is made on the basis of the patient's mental status, airway protective mechanisms, ability to cough and character of secretions. If the patient has an adequate sensorium with intact airway protection mechanisms, and is without excessive secretions, it is reasonable to extubate the trachea.

$\mathrm{COPD}=$ chronic obstructive pulmonary disease; $\mathrm{f} / \mathrm{V}_{\mathrm{T}}=$ rapid shallow breathing index; NIV = noninvasive ventilation; $\mathrm{PEEP}=$ positive end-expiratory pressure; $\mathrm{PSV}=$ pressure-support ventilation; SIMV = synchronized intermittent mandatory ventilation. 


\begin{tabular}{|c|c|c|c|c|c|c|}
\hline \multirow[b]{2}{*}{ Reference } & \multirow[b]{2}{*}{ Patients } & \multirow{2}{*}{$\begin{array}{c}\text { Pretest probability } \\
\text { of weaning } \\
\text { success }(\%)\end{array}$} & \multicolumn{2}{|c|}{ Likelihood ratio (95\% Cl) } & \multicolumn{2}{|c|}{$\begin{array}{l}\text { Post-test probability of } \\
\text { weaning success (\%) }\end{array}$} \\
\hline & & & Positive* & Negative $^{\dagger}$ & Positive* & Negative $^{\dagger}$ \\
\hline [6] & 64 Medical patients & 56 & $2.72(1.50-5.17)$ & $0.04(0.00-0.37)$ & $77(65-87)$ & $5(0-32)$ \\
\hline [10] & 100 Medical patients & 63 & $1.49(1.04-2.35)$ & $0.27(0.08-0.88)$ & $72(64-79)$ & $31(12-60)$ \\
\hline [11] & 185 Postoperative patients & 92 & $1.45(1.07-2.56)$ & $0.09(0.02-0.54)$ & $94(92-97)$ & $51(17-86)$ \\
\hline [12] & 49 Medical patients (aged $>70$ years) & 77 & $2.70(0.93-11.7)$ & $0.36(0.15-1.10)$ & $90(76-97)$ & $55(33-79)$ \\
\hline
\end{tabular}

Results are expressed as likelihood ratio. *Positive test result is a value of rapid shallow breathing index $\left(\mathrm{f} / \mathrm{V}_{\mathrm{T}}\right)$ lower than 105 or 100 ; ${ }^{\dagger}$ negative test result is a value of $f / V_{T}$ higher than 105 or 100 .

A team approach and an organized problem-orientated plan are important to expedite successful discontinuation of mechanical ventilation. Ely et al [4] recently demonstrated that a protocol of weaning is superior to the physician's individual decision-making at the bedside. They enrolled $\mathbf{3 0 0}$ mechanically ventilated medical and nonsurgical cardiac patients into a randomized, controlled trial in which the treatment group was weaned using a two-step process of daily screening by respiratory care practitioners followed by spontaneous breathing trials when recovery was sufficient to pass the daily screen. Those investigators found that removal from mechanical ventilation was 2 days earlier in the protocol-directed group. The use of the protocol to manage just four patients (95\% confidence interval 3-5) would result in one individual being off mechanical ventilation after $48 \mathrm{~h}$ who otherwise would not have been.

Practice guidelines on weaning should be based on carefully performed clinical studies. Few areas in critical care have been evaluated as extensively by well-designed studies over the past decade as the discontinuation of mechanical ventilation. Therefore, every step in the process of weaning is supported by the results of at least one randomized clinical trial. In the present review the procedures that should be incorporated into a weaning algorithm are discussed, taking into account the results of the aforementioned studies.

\section{Predictive weaning criteria: how useful are they?}

Weaning procedures are usually started only after the underlying disease process that necessitated mechanical ventilation has significantly improved or is resolved. The patient should also have an adequate gas exchange (most studies define this condition as an arterial oxygen tension/fractional inspired oxygen ratio higher than 200), appropriate neurological and muscular status, and stable cardiovascular function.
Weaning indices are objective criteria that are used to predict the readiness of patients to maintain spontaneous ventilation. Some parameters based on respiratory mechanics, gas exchange, and breathing pattern have been proposed as useful predictors of weaning outcome that could guide clinicians in determining the optimal time to discontinue mechanical ventilation [6-9].

Several studies $[6,10-12]$ have demonstrated that the rapid shallow breathing index ( $f / V_{T}$, where ' $f$ ' is the respiratory rate and ' $\mathrm{V}_{\mathrm{T}}$ ' is the tidal volume measured during the first minute of a T-piece trial) is superior to conventional parameters in predicting the outcome of weaning. With this in mind, the main issue is how useful is the $f / V_{T}$ ratio to distinguish between patients who will and those who will not wean successfully.

The possibilities of weaning success before an attempt of weaning (pretest probability) can be estimated by experienced physicians according to the setting in which they work and the sorts of patients they see. The post-test probability is the probability of weaning success, taking into account the results (positive or negative) of a diagnostic test such as the measurement of the $f / V_{T}$ ratio. Clinicians want to know how the result of the $f / V_{T}$ measurement alters the probability of weaning success. The direction and magnitude of the change from pretest to post-test probability are determined by the likelihood ratio. Likelihood ratios greater than 1 increase the probability of weaning success; and the higher the likelihood ratio, the greater this increase. Conversely, likelihood ratios less than 1 decrease the probability of weaning success, and the smaller the likelihood ratio, the greater the decrease in probability and the smaller its final value. Likelihood ratios greater than 10 or less than 0.1 indicate large and often conclusive differences between pretest and post-test probability. Likelihood ratios of 5-10 and 0.1-0.2 indicate moderate differences between pretest and post-test prob- 
Table 2

Changes from pretest probability of weaning success to post-test probability for different likelihood ratios obtained in several studies that evaluated the $f / V_{T}$ ratio

\begin{tabular}{|c|c|c|c|c|c|c|c|c|}
\hline \multirow{3}{*}{$\begin{array}{l}\text { Pretest probability } \\
\text { of weaning success } \\
(\%)\end{array}$} & \multicolumn{8}{|c|}{ Post-test probability of weaning success (\%) } \\
\hline & \multicolumn{4}{|c|}{ Likelihood ratio of a positive test result ${ }^{*}$} & \multicolumn{4}{|c|}{ Likelihood ratio of a negative test result ${ }^{\dagger}$} \\
\hline & 1.45 & 1.51 & 2.69 & 2.74 & 0.05 & 0.09 & 0.27 & 0.36 \\
\hline 30 & 38 & 39 & 53 & 54 & 2 & 4 & 10 & 13 \\
\hline 40 & 49 & 50 & 64 & 65 & 3 & 6 & 15 & 19 \\
\hline 50 & 59 & 60 & 73 & 73 & 5 & 8 & 21 & 26 \\
\hline 60 & 68 & 69 & 80 & 80 & 7 & 12 & 29 & 35 \\
\hline 70 & 70 & 77 & 86 & 86 & 10 & 17 & 39 & 46 \\
\hline 80 & 85 & 86 & 91 & 92 & 17 & 26 & 52 & 59 \\
\hline
\end{tabular}

${ }^{*}$ Positive test result is a value of rapid shallow breathing index $\left(f / V_{T}\right)$ lower than 105 or 100 ; ${ }^{t}$ negative test result is a value of $f / V_{T}$ higher than 105 or 100 .

ability. Likelihood ratios of 2-5 and 0.5-0.2 generate small changes from pretest to post-test probability and likelihood ratios of $1-2$ and $0.5-1$ alter probability to a small degree [13]. A likelihood ratio of 3 for an $f / V_{T}$ lower than 100 means that a value of $f / V_{T}$ lower than 100 is three times more likely to occur in a patient who will subsequently wean successfully from mechanical ventilation than it is to occur in a patient who will fail to wean.

None of the studies that evaluated the accuracy of the $f / V_{T}$ ratio to predict successful weaning $[6,10-12]$ expressed results as likelihood ratios, but we have calculated them by using the values of sensitivity and specificity reported by the authors in each study (Table 1). Taking into account the likelihood ratios, we have also calculated the post-test probability of weaning success for different pretest probabilities (Table 2). When the pretest probability of weanability is high $(\geq 70 \%)$ establishing the $f / V_{T}$ value may be useless in the decision-making process, because a value lower than 100 would only confirm that it is very likely that the patient will wean and a value higher than 100 would not necessarily dismiss success because post-test probabilities between 40 and $60 \%$ are possible. Conversely, when the pretest probability of weanability is low $(\leq 40 \%)$ establishing the $f / V_{T}$ value may be very useful; this is because a value higher than 100 might dismiss an attempt at weaning since the probability of success will be lower than $20 \%$, and a value lower than 100 could encourage an attempt at weaning, taking into account that probabilities of success between 50 and $65 \%$ are possible.

Several studies [10-12] have reported that pretest probability of weaning success ranges from 50 to $70 \%$ when patients are identified by clinical judgement as being ready to be weaned. Table 2 shows that a $f / V_{T}$ value higher than 100 is helpful in averting attempts at weaning in a popula- tion of patients with pretest probabilities of weaning success that are lower than 50\%. Moreover, the usefulness of a $\mathrm{f} / \mathrm{V}_{\mathrm{T}}$ ratio value higher than 100 to decide on readiness for weaning remains controversial when used in populations of patients with pretest probabilities of 50-70\%, who may have post-test probabilities of weaning success that range from 5 to $46 \%$. In such cases, most physicians would not attempt to wean the patient when the post-test probability of success is lower than $20 \%$, but it is also possible that some physicians may decide to attempt weaning when the post-test probability of weaning success is higher than $30 \%$.

\section{Is the patient able to sustain spontaneous breathing?}

Once a patient has been considered ready to be weaned, the best method to assess whether the patient is able to breathe on his or her own is to perform a trial of spontaneous ventilation. Ely et al [4] showed that immediate extubation after successful trials of spontaneous breathing expedites weaning and reduces the duration of mechanical ventilation as compared with a more gradual discontinuation of ventilatory support. Several studies $[1-5,14,15]$ have demonstrated that $60-80 \%$ of mechanically ventilated patients can be successfully extubated after passing a trial of spontaneous breathing.

Pressure-support, continuous positive airway pressure and T-piece trials are the most common methods used to test the readiness for liberation from mechanical ventilation. Few randomized studies $[3,16]$ have evaluated the best technique for performing spontaneous breathing trials before extubation. The first study that dealt with this issue [16] compared continuous positive airway pressure of $5 \mathrm{cmH}_{2} \mathrm{O}$ and T-piece in a group of 106 mechanically ventilated patients who underwent a 1 -h trial of sponta- 
neous breathing, and no difference in the percentage of patients failing extubation was found. Because the endotracheal tube imposes a resistive load on the respiratory muscles that is inversely related to its cross-sectional diameter, some clinicians advocate use of $5-8 \mathrm{cmH}_{2} \mathrm{O}$ pressure support to offset this imposed load. With this in mind, the study performed by the Spanish Lung Failure Collaborative Group [3] compared weaning outcome after trials of spontaneous breathing with either T-tube or pressure support of $7 \mathrm{cmH}_{2} \mathrm{O}$, but no difference was observed in the percentage of patients who remained extubated for $48 \mathrm{~h}(63 \%$ in the group assigned to T-tube and $70 \%$ in the group assigned to pressure support; $P=0.14$ ).

The duration of a spontaneous breathing trial has been set at $2 \mathrm{~h}$ in most studies $[1,2,4,14,15]$. One prospective, multicenter, randomized trial of 526 patients [5] found that trials of spontaneous breathing for 30 or 120 min were equivalent in identifying patients who could tolerate extubation, and that patients had reintubation rates of approximately $13 \%$ at $48 \mathrm{~h}$ regardless of the duration of their T-tube trial.

Precise criteria for terminating a weaning trial do not exist, and currently trials are terminated on the basis of the clinical judgement of the physician. There are two types of criteria used to determine whether a patient passes or fails a spontaneous breathing trial: objective criteria (abnormal arterial blood gas measurements) and subjective criteria (diaphoresis, evidence of increasing effort, tachycardia, agitation, anxiety). Patients have clearly failed a spontaneous breathing trial if they develop hypercapnia or hypoxaemia. The evaluation of clinical tolerance to spontaneous breathing by using exclusively subjective criteria has important drawbacks; on the one hand, strict criteria might increase the occurrence of unnecessarily prolonged mechanical ventilation but, on the other hand, permissive criteria might increase the occurrence of reintubation. Randomized studies are needed to compare outcome of weaning in patients whose clinical tolerance to spontaneous breathing trials is evaluated using either strict criteria or less strict criteria. Meanwhile, we recommend the criteria used by the Spanish Collaborative Group in their studies [1,3,5], because those criteria identify patients with a high probability of weaning success $(60-80 \%)$ and a reasonable reintubation rate within $48 \mathrm{~h}(13-18 \%)$. Those criteria are as follows: respiratory frequency of more than 35 breaths/min; arterial oxygen saturation below 90\%; heart rate above 140 beats/minute or a sustained increase or decrease in the heart rate of more than 20\%; systolic blood pressure above $180 \mathrm{mmHg}$ or below $90 \mathrm{mmHg}$; agitation; diaphoresis; and anxiety or signs of increased work of breathing (accessory muscle use, paradoxical or asynchronous rib cage-abdominal breathing movements, intercostal retractions, nasal flaring).
Once a patient is able to sustain spontaneous breathing, a second judgement must be made regarding whether the artificial airway can be removed by assessing the patient's mental status, airway protective mechanisms, ability to cough and character of secretions.

It is our contention that there is little risk in performing a closely observed trial of spontaneous breathing in patients in whom any acute respiratory failure has resolved and who are awake and cardiovascularly stable, in order to assess their ability to sustain spontaneous breathing. When the patient remains clinically stable with no signs of poor tolerance until the end of the trial, the endotracheal tube should be immediately removed. If the patient develops signs of poor tolerance, weaning is considered to have failed and mechanical ventilation is reinstituted.

\section{What about patients failing the first attempt at weaning?}

Weaning attempts that are unsuccessful usually indicate incomplete resolution of the illness that precipitated the need for mechanical ventilation, or the development of new problems. Failure to wean has been attributed to an imbalance between the load faced by the respiratory muscles and their neuromuscular competence. If a compensated balance of strength and load cannot be restored, attempts at spontaneous breathing will be futile. Therefore, once a patient fails a spontaneous breathing trial, the clinician must comprehensively evaluate the patient, looking for ways to improve his or her physiologic status.

Failure to wean is usually multifactorial. Table 3 shows a number of reasons that contribute to weaning failure. A review of pathophysiological aspects of difficult weaning is beyond the scope of the present review, but any factors that may lead to failure to wean deserve mention, because they are frequently observed in ventilated patients and can be ameliorated with little effort.

A highly illustrative example of how different factors can lead to imbalance between ventilatory needs and respiratory capability is provided by acutely hyperinflated patients. In these patients, the load of the inspiratory muscles is increased for a variety of reasons. First, airway obstruction and/or decreased elastic recoil lead to prolongation of expiration that cannot be completed before the ensuing inspiration. It implies that at the end of an expiration there is still a positive pressure at the alveolar level. Consequently, during the next inspiration the inspiratory muscles have to develop an equal amount of pressure before airflow begins. Second, because of hyperinflation tidal breathing occurs at a steeper portion of the pressure-volume curve of the lung, further increasing the load. At the same time that the load is severely increased, the neuromuscular competence is decreased due to muscular 
Table 3

Factors that can lead to weaning failure due to the imbalance between ventilatory needs and respiratory capacity

Factors that increase the load

\begin{tabular}{lll} 
Increased resistive loads & Increased chest wall elastic loads & Increased lung elastic loads \\
\hline Bronchospasm & Pleural effusion & $\begin{array}{l}\text { Hyperinflation (intrinsic positive end-expiratory } \\
\text { pressure) }\end{array}$ \\
Airway edema, secretions & Pneumothorax & Alveolar oedema \\
Upper airway obstruction & Flail chest & Infection \\
Obstructive sleep apnea & Obesity & Atelectasis \\
Endotracheal tube kinking & Ascites & Interstitial inflammation and/or oedema \\
Secretions encrustation & Abdominal distension & \\
Ventilatory circuit resistance & & \\
\hline
\end{tabular}

Factors that result in decreased neuromuscular competence

\begin{tabular}{lll} 
Decreased drive & Muscle weakness & Impaired neuromuscular transmission \\
\hline Drug overdose & Electrolyte derangement & Critical illness polyneuropathy \\
Brain-stem lesion & Malnutrition & Neuromuscular blockers \\
Sleep deprivation & Myopathy & Aminoglycosides \\
Hypothyroidism & Hyperinflation & Guillain-Barré syndrome \\
Starvation/malnutrition & Drugs, corticosteroids & Mysthenia gravis \\
Metabolic alkalosis & Sepsis & Phrenic nerve injury \\
Myotonic dystrophy & & Spinal cord lesion \\
\hline
\end{tabular}

weakness. Hyperinflation forces the inspiratory muscles to operate at an unfavourable position in their length-tension curve. In a state of hyperinflation the costal and crural fibres of the diaphragm are arranged in series, rather than in parallel, and this diminishes the force that can be generated. The resultant flattening of the diaphragm increases its radius of curvature and, according to Laplace's law $\left(P_{d i}\right.$ $=2 \mathrm{~T}_{\mathrm{di}} / \mathrm{R}_{\mathrm{di}}$; where $\mathrm{P}_{\mathrm{di}}$ is the pressure-generating capacity, $T_{d i}$ is the tension and $R_{d i}$ is the radius of curvature), diminishes its pressure-generating capacity for a given tension developed.

Hyperinflation is quite common in chronic obstructive pulmonary disease (COPD) patients, and could have a pivotal role in the failure of weaning, so the measurement of intrinsic positive end-expiratory pressure $\left(P E E P_{j}\right)$ should be considered in every COPD patient who fails a weaning attempt. Given the detrimental effects of PEEP in increasing the load, every effort should be made to decrease it. Reducing the severity of airway obstruction by maximizing bronchodilator treatment, adjusting ventilator settings to provide as much time as possible for complete exhalation to occur, and improving tolerance to spontaneous breathing by decreasing the work of inspiration through the addition of external PEEP are proper therapeutic interventions [17-20]. The addition of external PEEP does not cause further hyperinflation or adversely affect haemodynamics or gas exchange, provided that the added PEEP is less than approximately $85 \%$ of the level of PEEP ${ }_{i}$ [20].

A number of studies performed in small and highly selected populations of COPD patients have found a fatiguing pattern in the electromyogram power spectrum in mechanically ventilated patients during unsuccessful weaning trials $[21,22]$. These changes have been interpreted as proof that failure to wean from mechanical ventilation may be due to diaphragm fatigue, and that is the final common pathway that leads to the development of hypercapnic respiratory failure. Because respiratory muscle fatigue probably develops during unsuccessful weaning and it is possible that it leads to persistent ventilator dependency, a major issue in the weaning approach is to provide rest for the respiratory muscles and allow them to recover from fatigue. One study that evaluated a group of healthy individuals in whom diaphragmatic fatigue was induced [23] found that diaphragmatic contractility remained significantly depressed for at least $24 \mathrm{~h}$. Recovery from fatigue might be even slower in difficult-towean patients. Resting the respiratory muscles with 
mechanical ventilation is the only method of treating muscle fatigue. With this in mind, an expert panel recommended increasing ventilator support at night as a way to provide periods of rest in the management of difficult-towean patients [24].

With most modes of assisted ventilation, the inspiratory muscles do not stop contracting once the ventilator has been triggered. Therefore, ventilator support should not be considered synonymous with respiratory rest. When the settings are not optimally set, the patient's active work may be even greater than that required for spontaneous chest inflation without mechanical ventilation [25]. A mode of ventilation that provides inadequate respiratory muscle rest is likely to delay rather than facilitate weaning, and therefore careful adjustment of the ventilator settings is necessary to minimize to the maximum the respiratory work. Trigger sensitivity and inspiratory flow rate are the factors that primarily determine the patient's work of breathing during mechanical ventilation. The importance of a high peak flow setting when pressure support is used has been demonstrated in a prospective study that involved COPD patients [26], in which the time to reach the set plateau pressure was manipulated with the aim of modulating the initial flow rate; the more rapidly the pressure plateau was achieved, the higher was the initial flow rate. Lengthening the pressure rise time almost invariably increased the patient's work of breathing, as well as several other indices of patient effort, whereas the breathing pattern was essentially not modified. The method of triggering, either by pressure or flow, may be also an important determinant of the patient effort during mechanical ventilation. Although a number of studies in COPD patients have shown that a flow-triggered system decreases work of breathing in comparison with a pressure-triggered system during continuous positive airway pressure or synchronized intermittent mandatory ventilation (SIMV) [27,28], other authors $[29,30]$ have reported that the triggering system of the mechanical ventilator does not have influence on work of breathing.

Optimal plumbing of the respiratory circuit is of major importance in minimizing respiratory work during a trial of spontaneous breathing. Important factors include the resistance of the endotracheal tube, equipment dead space, and resistance of the inspiratory circuit and humidifier. It has been demonstrated $[31,32]$ that heat-moisture exchangers increase resistance to flow and add a substantial amount of dead space when compared with heated humidifiers. Although in many patients the amount of added dead space with heat-moisture exchangers is trivial and unlikely to adversely affect weaning trial outcome, this may not be the case in patients who have limited ventilatory reserve, such as the majority of difficultto-wean patients.
In patients with repeatedly unsuccessful weaning trials, a gradual withdrawal from mechanical ventilation can be attempted while factors responsible for the ventilatory dependence are corrected. The most common methods of discontinuing mechanical ventilation are SIMV, pressure-support ventilation (PSV) and T-tube. Two welldesigned, randomized, multicenter studies [1,2] have compared the above methods of weaning. Brochard et al [2] studied 456 medical-surgical patients being considered for weaning. Three hundred and forty-seven patients (76\%) were successfully extubated after a single 2-h Tpiece trial. The remaining 109 patients (24\%) who failed an initial trial of spontaneous breathing were randomized to be weaned by one of three strategies: T-piece trials of increasing duration until $2 \mathrm{~h}$ could be tolerated; SIMV with attempted reductions of two to four breaths/min, twice a day, until four breaths/min could be tolerated; and PSV with attempted reductions of $2-4 \mathrm{cmH}_{2} \mathrm{O}$ twice a day until $8 \mathrm{cmH}_{2} \mathrm{O}$ could be tolerated. Patients randomized to the three strategies were similar with regard to disease severity and duration of ventilation before weaning. There was no difference in the duration of weaning between the T-piece and SIMV groups, but PSV led to significantly shorter duration of weaning compared with the combined T-piece and SIMV cohorts (5.7 \pm 3.7 days versus $9.3 \pm 8.2$ days).

Esteban et al [1] performed a similar study of 546 medical-surgical patients. In that study, 416 (76\%) patients were successfully extubated on their first day of weaning after a T-piece trial. The 130 patients who failed were randomized to undergo weaning by the following strategies: once a day T-piece trial; two or more T-piece or continuous positive airway pressure trials each day as tolerated; PSV with attempts at reduction of $2-4 \mathrm{cmH}_{2} \mathrm{O}$ at least twice a day; and SIMV with attempts at reduction by two to four breaths/min at least twice a day. Patients assigned to the four groups were similar with regard to demographic characteristics, acuity of illness and cardiopulmonary variables. The weaning success rate was significantly better with once daily and multiple T-trials than with PSV and SIMV. PSV was not superior to SIMV. The median duration of weaning was 5 days for SIMV, 4 days for PSV and 3 days for the T-piece regimens.

The studies by Brochard et al [2] and Esteban et al [1] yielded two important common conclusions: first, the pace of weaning depends on the manner in which the technique is applied; and second, that SIMV is the least efficient technique of weaning. With respect to PSV and intermittent trials of T-tube, a clear superiority of one technique over the other has not yet been established. The conflicting results in those studies concerning these two techniques may be explained, at least in part, by differences among the two studies in the criteria for weaning progress and the criteria for extubation. 


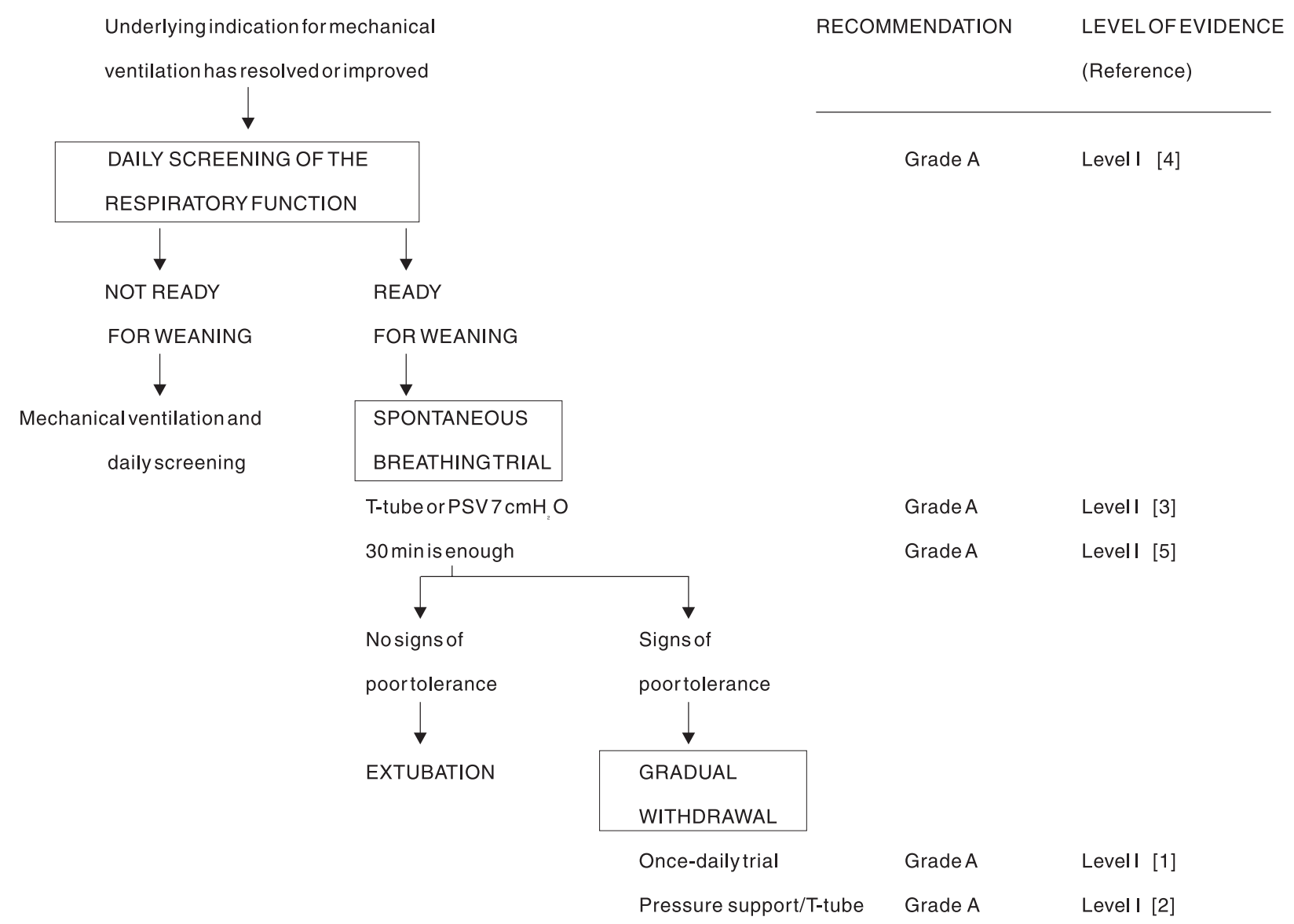

Algorithm for discontinuation of mechanical ventilation. PSV, pressure-support ventilation.

\section{Role of noninvasive mechanical ventilation in the weaning process}

Two randomized studies $[33,34]$ have evaluated the usefulness of noninvasive ventilation (NIV) as a weaning technique. In the study by Nava et al [33], 50 COPD patients who failed a T-tube trial after $36-48 \mathrm{~h}$ of mechanical ventilation were randomized to either immediate extubation with noninvasive pressure support via a face mask and a standard ventilator, or continued pressure support via an endotracheal tube. Both groups underwent trials of spontaneous breathing at least twice each day and reductions in the pressure support level of $2-4 \mathrm{cmH}_{2} \mathrm{O} /$ day as tolerated in an attempt to discontinue mechanical ventilation entirely. Compared with patients who were weaned while intubated, the group that was weaned with NIV had a lower rate of nosocomial pneumonia (0\% versus $28 \%$ ), a significantly higher weaning rate at 60 days $(88 \%$ versus $68 \%)$, and a significantly lower 60 -day mortality rate (8\% versus $28 \%$ ).
In the study by Girault et al [34], 33 patients with chronic respiratory failure who failed a 2-h T-piece weaning trial of spontaneous breathing were randomized to either extubation and NIV $(n=17)$ or conventional invasive PSV $(n=17)$. No differences were observed between the two groups with respect to clinical and functional characteristics, either at admission to the intensive care unit or at randomization. In the conventional invasive ventilation protocol, $75 \%$ of patients were successfully weaned and extubated versus $76.5 \%$ in the NIV group. As expected by the study design, the duration of endotracheal intubation was significantly shorter in the NIV group than in the control group (4.6 \pm 1.5 days versus $7.7 \pm 3.8$ days; $P=0.004$ ). The total duration of ventilatory support related to weaning, however, was significantly higher in the NIV group ( $11.5 \pm 5.2$ days versus $3.5 \pm 1.4$ days; $P<0.001$ ). The durations of intensive care unit and hospital stay and the 3-month survival were similar in the two groups. 
The use of NIV to facilitate weaning has not been evaluated in postoperative patients or in those with altered neurologic status, haemodynamic instability, or any of a number of severe concomitant diseases. Nonetheless, NIV may become an important weaning mode in selected patients if its success is replicated in other trials.

Very recently, Jiang et al [35] evaluated the role of NIV in preventing reintubation after elective or unplanned extubation. They conducted a prospective study in 93 extubated patients who were randomly assigned to receive either biphasic positive airway pressure via face mask or unassisted oxygen therapy. There was no significant difference in the percentage of patients who required reintubation (15\% in the unassisted oxygen therapy group and $28 \%$ in the biphasic positive airway pressure group).

\section{Conclusion}

At present, every step in the process of weaning is supported by the results of several randomized studies [1-5]. The algorithm presented in Figure 1 applies the findings of the above studies to clinical decision-making. The recommendations based on the evidence have been graded according to a published system [36].

The daily screening of patients who are on mechanical ventilation with the aim of identifying those able to breathe spontaneously is, possibly, the best approach to reduce the duration of ventilatory support. Standard weaning criteria were used in all of the aforementioned studies to identify patients who were able to resume spontaneous breathing, and patients who did not meet such criteria remained on mechanical ventilation. The ability to breathe spontaneously is adequately tested by performing a trial with either T-tube or pressure support of $7 \mathrm{cmH}_{2} \mathrm{O}$. A duration of $2 \mathrm{~h}$ has been extensively evaluated, but weaning outcome is the same when the duration is reduced to $30 \mathrm{~min}$. Patients failing the initial spontaneous breathing trial need a gradual withdrawal of ventilatory support. It is known that SIMV is the most ineffective method of weaning those patients. With respect to the use of pressure support or T-tube, clinicians should choose the method they feel most comfortable with and individualize the strategy to meet the patient's needs. We recommend the use of a once daily trial of spontaneous breathing in difficult-to-wean patients for three main reasons: it leads to extubation twice as quickly as PSV; it simplifies management, because the patient's ability to breathe without ventilatory support needs to be assessed only once a day; and it allows a prolonged period of rest, which may be the most effective method to permit adequate time for muscle recovery.

\section{References}

1. Esteban A, Frutos F, Tobin MJ, et al: A comparison of four methods of weaning patients from mechanical ventilation. $N$ Engl J Med 1995, 332:345-350.
2. Brochard L, Rauss A, Benito S, et al: Comparison of three methods of gradual withdrawal from ventilatory support during weaning from mechanical ventilation. Am J Respir Crit Care Med 1994, 150: 896-903.

3. Esteban A, Alia I, Gordo F, et al: Extubation outcome after spontaneous breathing trials with T-tube or pressure support ventilation. Am J Respir Crit Care Med 1997, 156:459-465.

4. Ely EW, Baker AM, Dunagan DP, et al: Effect on the duration of mechanical ventilation of identifying patients capable of breathing spontaneously. N Engl J Med 1996, 335:1864-1869.

5. Esteban A, Alia I, Tobin MJ, et al: Effect of spontaneous breathing trial duration on outcome of attempts to discontinue mechanical ventilation. Am J Respir Crit Care Med 1999, 159:512-518.

6. Yang $\mathrm{KL}$, Tobin MJ: A prospective study of indexes predicting the outcome of trials of weaning from mechanical ventilation. $N$ Engl $J$ Med 1991, 324:1445-1450.

7. Sassoon CSH, Mahutte CK: Airway occlusion pressure and breathing pattern as predictors of weaning outcome. Am Rev Respir Dis 1993, 148:860-866.

8. Jabour ER, Rabil DM, Truwit JD, Rochester DF: Evaluation of a new weaning index based on ventilatory endurance and the efficiency of gas exchange. Am Rev Respir Dis 1991, 144:531-537.

9. Levy MM, Miyasaki A, Langston D: Work of breathing as a weaning parameter in mechanically ventilated patients. Chest 1995, 108: 1018-1020.

10. Chatila W, Jacob B, Guaglionone D, Manthous CA: The unassisted respiratory rate-tidal volume ratio accurately predicts weaning outcome. Am J Med 1996, 101:61-67.

11. Jacob B, Chatila W, Manthous CA: The unassisted respiratory rate/tidal volume ratio accurately predicts weaning outcome in postoperative patients. Crit Care Med 1997, 25:253-257.

12. Krieger BP, Isber J, Breitenbucher A, Throop G, Ershowsky P: Serial measurements of the rapid-shallow-breathing index as a predictor of weaning outcome in elderly medical patients. Chest 1997, 112:1029-1034.

13. Jaeschke R, Guyatt GH, Sackett DL, for the Evidence-Based Medicine Working Group: How to use an article about a diagnostic test. What are the results and will they help me in caring from my patient? JAMA 1994, 271:703-707.

14. Reyes A, Vega G, Blancas R, et al: Early vs conventional extubation after cardiac surgery with cardiopulmonary bypass. Chest 1997, 112:193-201.

15. Vallverdú I, Calaf N, Subirana M, et al: Clinical characteristics, respiratory functional parameters, and outcome of a two-hour T-piece trial in patients weaning from mechanical ventilation. $A m J$ Respir Crit Care Med 1998, 158:1855-1862.

16. Jones DP, Byrne P, Morgan C, Fraser I, Hyland R: Positive end-expiratory pressure vs T-piece. Extubation after mechanical ventilation. Chest 1991, 100:1655-1659.

17. Petrof BJ, Legaré M, Goldberg P, Milic-Emili J, Gottfried SB: Continuous positive airway pressure reduces work of breathing and dyspnea during weaning from mechanical ventilation in severe chronic obstructive pulmonary disease. Am Rev Respir Dis 1990, $141: 281-289$.

18. Maclntyre NR, Cheng KC, McConnell R: Applied PEEP during pressure support reduces the inspiratory threshold load of intrinsic PEEP. Chest 1997, 111:188-193.

19. Sydow M, Golisch W, Buscher H, et al: Effect of low-level PEEP on inspiratory work of breathing in intubated patients, both with healthy lungs and with COPD. Intens Care Med 1995, 21:887-895.

20. Ranieri VM, Guliani R, Cinnella G, et al: Physiologic effects of positive end-expiratory pressure in patients with chronic obstructive pulmonary disease during acute ventilatory failure and controlled mechanical ventilation. Am Rev Respir Dis 1993, 147:5-13.

21. Cohen CA, Zagelbaum C, Gross D, Roussos Ch, Macklem PT: Clinical manifestation of inspiratory muscle fatigue. Am J Med 1982, 73:308-316

22. Brochard L, Harf A, Lorino $H$, Lemaire F: Inspiratory pressure support prevents diaphragmatic fatigue during weaning from mechanical ventilation. Am Rev Respir Dis 1989, 139:513-521.

23. Laghi F, D'Alfonso N, Tobin MJ: Pattern of recovery from diaphragmatic fatigue over 24 hours. J Appl Physiol 1995, 79:539-546.

24. Slutsky AS: ACCP Consensus Conference: mechanical ventilation. Chest 1993, 104:1833-1859.

25. Marini J, Rodriguez R, Lamb V: The inspiratory workload of patientinitiated mechanical ventilation. Am Rev Respir Dis 1986, 134: 902-909. 
26. Bonmarchand G, Chevron V, Chopin C, et al: Increased initial flow rate reduces inspiratory work of breathing during pressure support ventilation in patients with exacerbation of chronic obstructive pulmonary disease. Intens Care Med 1996, 22: 1147-1154.

27. Sassoon CSH, Del Rosario N, Fei R, et al: Influence of pressure and flow-triggered synchronous intermittent mandatory ventilation on inspiratory muscles work. Crit Care Med 1994, 22:1933-1941.

28. Sassoon $\mathrm{CSH}$, Lodia $\mathrm{R}, \mathrm{Rheeman} \mathrm{CH}$, et al: Inspiratory muscle work of breathing during flow-by, demand-flow and continuous flow systems in patients with chronic obstructive pulmonary disease. Am Rev Respir Dis 1992, 145:1219-1222.

29. Jager $\mathrm{K}$, Tweeddale $\mathrm{M}$, Holland $\mathrm{T}$ : Flow-triggering does not decrease the work of breathing and pressure-time product in COPD patients. Respir Care 1994, 39:892-896.

30. Tütüncü AS, Cakar N, Camci E, et al: Comparison of pressure- and flow-triggered pressure-support ventilation on weaning parameters in patients recovering from acute respiratory failure. Crit Care Med 1997, 25:756-760.

31. Le Bourdellès G, Mier L, Fiquet B, et al: Comparison of the effects of heat and moisture exchangers and heated humidifiers on ventilation and gas exchange during weaning trials from mechanical ventilation. Chest 1996, 110:1294-1298.

32. Iotti GA, Olivei MC, Palo A, et al: Unfavorable mechanical effects of heat and moisture exchangers in ventilated patients. Intens Care Med 1997, 23:399-405.

33. Nava S, Ambrosino N, Clini E, et al: Noninvasive mechanical ventilation in the weaning of patients with respiratory failure due to chronic obstructive pulmonary disease. Ann Intern Med 1998, 128: 721-728.

34. Girault C, Daudenthun I, Chevron V, et al: Noninvasive ventilation as a systematic extubation and weaning technique in acute-onchronic respiratory failure. A prospective, randomized controlled study. Am J Respir Crit Care Med 1999, 160:86-92.

35. Jiang JS, Kao SJ, Wang SN: Effect of early application of biphasic airway pressure on the outcome of extubation in ventilator weaning. Respirology 1999, 4:161-165.

36. Cook DJ, Guyatt GH, Laupacis A, Sackett DL: Rules of evidence and clinical recommendations on the use of antithrombotic agents. Chest 1992, 102 (suppl 4):305S-311S.

Authors' affiliation: Unidad de Cuidados Intensivos, Hospital Universitario de Getafe, Madrid, Spain

Correspondence: Inmaculada Alía, MD, Unidad de Cuidados Intensivos, Hospital Universitario de Getafe, Carretera de Toledo Km 12,5, Getafe 28905, Madrid, Spain. Tel: +34 9168 34982;

fax: +349168 32095 